\title{
LIST SIZE, COMPOSITION OF PRACTICE AND GENERAL PRACTITIONERS' WORKLOAD IN THE NETHERLANDS
}

\author{
Peter P. Groenewegen, ' Jack B. F. Hutten'² and Koos van der Velden ${ }^{1}$ \\ 'Netherlands Institute of Primary Health Care (NIVEL), P.O. Box 1568, 3500 BN Utrecht, \\ The Netherlands and 'Interuniversity Center for Sociological Theory and Methodology (ICS), \\ State University of Utrecht, The Netherlands
}

\begin{abstract}
Workload of general practitioners plays an important role in discussions about list size and remuneration in health care systems with fixed patient lists and capitation payments, such as in the Netherlands and in the United Kingdom.

Against the background of the fairness of differences in income level between GPs the question is posed to what extent differences in list size reflect differences in workload and to what extent differences in patient characteristics influence workload. Both list size and practice composition relate to the demand led character of general practice.

Data collected in the National Study of Morbidity and Interventions in General Practice are used. Central to this study is a three month recording of all contacts of 161 general practitioners (and their locums, assistant GPs and trainees) in the Netherlands. For each practice a patient register has been made to relate contacts to the practice population. The participating GPs kept a detailed diary covering $24 \mathrm{hr}$ a day during one week.

As indicators of workload several contact rates, hours worked in practice per week (in direct patient care and in other activities) and average length of office consultations are used.

Demand related characteristics have the strongest relation to the number of hours worked by GPs, particularly the number of hours spent in patient-related activities. Rates of contacts, with the exception of the office contact rate, are not related to list size, but mainly to practice composition. The average length of consultations is negatively related to list size and some characteristics of the practice population.
\end{abstract}

Key words-workload, general practice, list size, the Netherlands

\section{INTRODUCTION}

Workload of general practitioners (GPs) is an important issue in health care systems with capitation payment for GPs' services. Capitation payment implies a fixed amount of money per patient on an annual basis-sometimes differentiated by age groups in the practice population-irrespective of the amount of services actually rendered by the GPs. In relation to workload the question is posed whether or not the level of capitation payment justly reflects the amount of work generated by the practice population [1-3]. Both, factors on the 'demand' or 'patient' side and factors situated on the 'supply' side determine the level of workload of GPs [4]. The total number of patients on their list and composition of the practice population indicate the so called 'demand-related' influence on workload $[4,5]$. Particular characteristics of the practice population might be relevant because some groups of patients, for instance women and the elderly, contact their GP more often or longer than others. 'Supply-related' determinants of workload are e.g. organizational aspects of the practice and personal characteristics of the GP.

A 'fair' capitation system assumes a linear relation between list size and workload of GPs: when GPs have larger lists, they have to work harder and therefore earn more. However, it is conceivable that GPs with a comparable list size have a different workload due to differences in the composition of the practice, e.g. in age distribution. Capitation systems like the one in the U.K. take these differences into account by setting different capitation fees for different age groups. In the Dutch capitation system this kind of differentiation does not exist: fees are only determined by list size. This makes the question relevant whether or not list size is the main determinant on the 'demand' side of the GP's workload. In this paper we will answer this question. First we provide some background information on the Dutch remuneration system and specify the research question. Next we describe the data and methods used. The results are presented in the fourth section. The paper ends with a discussion of the results.

\section{BACKGROUND TO THE DUTCH CAPITATION SYSTEM AND RESEARCH QUESTIONS}

In January 19886275 GPs practised as principals in the Netherlands. Another 349 worked as an assistant to a principal and a number of GPs had a trainee in their practice. The number of inhabitants per principal was 2345; including assistants to a principal this number is 2221 [6]. Actual list size is a bit lower because some groups of the population do not use the normal GP services, e.g. those in military service, institutionalized people and so on. Single handed practice is the dominant form of organization ( $55 \%$ 
of the GPs). Thirty-one percent of the GPs are in partnerships of two GPs and $7 \%$ are in group practices of three or more GPs. Finally $8 \%$ of the GPs work in an integrated health care centre (where they work together with community nurses, social workers and in most cases physiotherapists). Nearly all GPs in the Netherlands work in independent practice. Only $5 \%$ works on a salaried basis, mainly in health care centres.

There are two groups of patients based on their insurance status: publicly insured patients $63 \%$ of the population) and privately insured patients $(37 \%$ of the population). Publicly insured patients are all employees (and their dependents) with a salary below a certain income ceiling, old age pensioners who used to be publicly insured before retirement and certain categories of social welfare dependents. The rest of the population is privately insured with one of the many private (profit or nonprofit) insurance companies. The payment system of GPs differs according to these two groups of patients. Publicly insured patients are formally on the list of GPs. The GP receives a fixed amount of money for each patient on the list, irrespective of the number of consultations or services. Privately insured patients are not formally on the list of a GP, but they usually consult the same GP. They pay directly to the GP for the consultation and/or services rendered. Whether or not they will be refunded depends on their insurance policy. Private insurance policies offer coverage of GP services to varying degrees: from complete coverage of GPs' services through various schemes with deductibles to no coverage at all. Hospital and specialist care are always covered by private insurance policies. All GPs have both privately and publicly insured patients, but the actual mix differs from practice to practice.

The system of payment for GPs services has been debated for the last 5-10 years. The debate centres around two topics. The first is the distinction between publicly and privately insured patients. There is agreement now that this distinction will be abolished by the introduction of a uniform system of insurance. The second is about the system of payment for GPs services under a uniform system of insurance. The original position of the GPs organization was that payment should be capitation based, possibly differentiated according to the amount of work associated with different groups of patients. During the last few years attention has shifted to a mixed system consisting of a lower capitation fee and additional fees for consultations and separate services, comparable to the system used in Denmark [7]. It seems probable that capitation will be part of the payment system of Dutch GPs, although in a different form than it is nowadays.

As indicated in the introduction, an assumption underlying undifferentiated capitation payment is that list size is the main determinant of workload of GPs. In the literature evidence is found for the influence of list size on workload. For U.K.'s National Health Service positive correlations are reported of list size with the number of consultations $[8,9]$ and with indicators of the number of hours worked and in particular the time spent in office consultations $[5,9]$. Negative correlations are found with the number of consultations per patient and with the length of consultations [5,8-11]. On the other hand, it is clear that other factors than list size influence the amount of work of GPs. Wilkin a.o. [9] did find that a higher percentage of elderly and of people from lower social class background in the practice population is associated with more time in direct patient care. However, they did not present a multivariate analysis including list size. It is a common finding in health care utilization research that women use GPs' services more frequently, as do the very young children and the elderly [12]. In the U.K., people with a higher social class background have somewhat more consultations, but lower class people have somewhat more home visits [13]. Unemployed men consult their GP more often than employed men [14]. In the Netherlands, publicly insured patients consume more medical services than privately insured patients $[15,16]$. Besides consultation rates the length of consultations is influenced by these characteristics of patients [17-19]. Finally, there is some evidence that the location of practice influences the workload of GPs [5], partly as a result of a higher demand for services among urban populations, but possibly also as a result of better accessibility of services [20].

The actual influence of these characteristics on the workload in general practice depends on the amount of variation between practices. The relative influence of list size compared to other demand related factors has not been assessed in the literature. Therefore, in this article the question is posed: What is the relative influence of personal list size on one hand and of practice composition on the other hand on the workload of Dutch general practitioners?

\section{DATA AND METHODS}

The study presented here is part of a large project, the National Survey of Morbidity and Interventions in General Practice [21]. Central to this project is a three month recording of all contacts of 161 general practitioners (and their trainees, locums and assistants) in the Netherlands. In this article data on the 161 independent GPs and 7 permanent locums/ assistant GPs are analyzed.

Selection of participating GPs is based on a stratified (according to region, urbanization and distance to a general hospital), random sample. Next to the 98 randomly selected GPs, 5 volunteering GPs and 58 GPs who were partners of these originally selected GPs participated. Data recorded include patient characteristics, characteristics of the consultation (e.g. first or repeat consultation, length of 
consultation, time of the day), complaints of the patient, diagnosis, and intervention (diagnostic services, treatment, prescriptions, referral). For all practices $(N=103)$ an age/sex register has been set up to be able to relate the contacts to the practice population. This register contains information about 335,000 patients. Out of the participating general practitioners $155 \mathrm{kept}$ a detailed diary covering $24 \mathrm{hr}$ a day during one week (including the weekend) within the three months recording period.

\section{Dependent variables}

In the literature different indicators of workload are used [4]. They can be divided in three groups: indicators based on rates of contact of patients, indicators based on the time GPs spent in different activities and the average length of consultations. We will use indicators from each of these groups.

(a) Rates of contact. The number of contacts, during the 3 months of registration, divided by the personal list size of the GP, expresses the relative workload, given the size of the practice population. Contacts can be handled by the practice secretaries or by the GPs themselves. It is also important to distinguish between office consultations and home visits of GPs. Both patients and GPs can be the initiator of the consultation. If the relative number of contacts initiated by patients is larger, the workload generated by the practice population will be larger. Therefore, four different kind of contact rates will be used.

- Total contact rate: all contacts in the practice, handled by GP or practice secretary;

-office contact rate: all office consultations handled by the GP;

-home visit rate: all home visits conducted by the GP;

-patient initiated contact rate: all contacts that, according to the GP, were initiated by the patients themselves.

Contacts of trainees and temporary locums or assistant GPs were added to the contacts of their principal GP because they had no personal lists.

(b) Time spent in practice activities. The diaries kept during one week, were used to compute the time GPs spent in practice. Hours on call/on duty were only taken into account as far as they included actual work. This variable is labelled total hours worked in practice. A distinction was made between two groups of activities namely direct patient care and other activities such as practice administration, education and consultations with colleagues. Hours spent in both kinds were separately analyzed. Inclusion of all hours on duty, irrespective of actual practice activities, would do justice to an important aspect of workload of GPs. On the other hand, this would make a comparative analysis of the relation between list size and hours worked difficult. Large differences in the number of hours worked could be caused by the fact that some GPs were on duty during the week they kept the diary, while others were not [22].

(c) Average length of consultations. Time spent on each individual patient is the third kind of indicator. Particular groups of patients need more time in a consultation than others. To control for differences in travelling time involved in home visits, we have computed the average length of office consultations only.

\section{Independent variables}

The independent variables are list size and aspects of the practice composition.

(a) List size. The total number of patients per practice was established through the patient register that was set up for each practice. This includes privately as well as publicly insured patients. The practice list size was transformed into an indicator of the personal list size. In the case of single handed practices personal list size equals practice list size. Patients in partnerships or health care centres were asked which GP they usually visit. Patients who did not report one particular GP were distributed over the partners according to their full-time equivalents of involvement in the practice, established at the beginning of the registration period. Trainees and temporary locums or assistants have not been included in the measurement of personal list size. Permanent assistant GPs were treated in the same way as partners, i.e. they have been assigned a personal list size according to full time equivalents of involvement in the practice.

(b) Practice composition. Based on earlier research [4], the following indicators of practice composition are used in the analyses:

-percentage of women;

- percentage of elderly people (over $75 \mathrm{yr}$ of age);

- percentage of young children (under $5 \mathrm{yr}$ of age);

-percentage of publicly insured patients;

- percentage of unemployed people;

-percentage of people with a foreign nationality;

- percentage of low educated people (people over $25 \mathrm{yr}$ of age with primary education only).

- degree of urbanization is included because of the possible differences between urban and rural areas as mentioned before.

The relative influences of list size and practice composition on indicators of workload are tested in a two-step multiple regression analysis. In the first step list size is separately included in the equation. In the second step aspects of practice composition are added. By comparing the explained variances $\left(R^{2}\right)$ of the equations, we can test whether the second equation provides significantly better predictions than the first one. If so, the standardized regression coefficients are considered to indicate the variables with the largest contribution. 


\section{RESULTS}

\subsection{The workload of the GPS}

Table 1 shows the main descriptive statistics of the variables used in the analyses. The average total contact rate during the three months of registration is 1.18. This means that on the average each patient on the list contacts the GP's practice once in three months. However, there is a large variation between GP's practices in this respect. In general, the number of office contacts is five times as high as the number of home visits. Most contacts are initiated by the patients.

The 155 GPs who completed the diary work $48 \mathrm{hr}$. As indicated before, hours on duty in which no actual practice activities were noted, were excluded. There is a large variation: some GPs work only one day a week in the practice, others for more than $75 \mathrm{hr}$. About $71 \%$ of that time is spent in direct patient care. The average length of office consultations is $8.4 \mathrm{~min}$.

The average personal list contains almost 2000 patients. Fifty-two percent of the practice population consists of women. There is only small variation between practices in this respect. The age distribution of the practice populations is indicated by the percentage of very old people (75 yr and older) which averages $5 \%$, and the percentage of very young people (under 5 yr of age) which averages $7 \%$. Sixtyone percent is publicly insured, $5 \%$ unemployed, $2 \%$ of foreign nationality and $16 \%$ of lower educational level.

The correlations between the indicators of workload are given in Table 2 . Of course the correlations between the indicators of the same group are high. The total contact rate correlates significantly with the other rates. Especially the office contact rate is strongly associated with the rate of contacts in- itiated by the patients. No significant relation is found between the home visit rate and the office contact rate. This might indicate that a higher demand for office consultations is not compensated by less home visits or vice versa.

The correlations between indicators of the allocation of time show that the total working time per week is more strongly related to direct patient care than to other activities in the practice like administration and education. It is interesting to see that the amount of time spent in direct patient care correlates negatively with the number of hours in non-patientrelated activities: the more time GPs spent in patient related activities, the less time they spent in other activities.

The correlations between indicators in different groups are sometimes contrasting. The total contact rate is not significantly related to any indicator in the other groups. The office contact rate has a negative relation with the hours spent in practice, especially in direct patient care. On the other hand, the number of home visits per patient on the list, has a positive relation with the hours spent in direct patient care per week. So, controlling for list size, GPs who provide more home visits work more hours per week in direct patient care. Furthermore the correlations show that the average length of office consultations is negatively associated with the home visit rate.

\subsection{List size as a determinant of workload}

In this section the zero order correlations between personal list size and the indicators of GP's workload will be explored. In Figs 1-3 personal list size is divided into seven groups. For each group the average score on the indicators is computed. The correlation coefficients are based on the unclassified list sizes.

Table 1. Descriptive statistics'

\begin{tabular}{lccccc}
\hline & Mean & Min & Max & SD & $N$ \\
\hline Rates of contact & & & & \\
Total contacts & & & & & \\
Office contacts & 1.18 & 0.65 & 1.99 & 0.27 & 168 \\
Home visits & 0.62 & 0.35 & 1.29 & 0.14 & 168 \\
Contacts initiated by patients & 0.14 & 0.02 & 0.38 & 0.71 & 168 \\
Working hours (per week) & 0.56 & 0.32 & 1.02 & 0.14 & 168 \\
Total hours worked & & & & & \\
Hours in direct patient care & 48.1 & 8.0 & 78.5 & 11.2 & 155 \\
Hours in other practice activities & 33.7 & 6.0 & 55.8 & 9.8 & 155 \\
Average length of consultations (min) & 14.4 & 0.0 & 21.3 & 3.7 & 155 \\
Personal list size & 8.4 & 3.2 & 14.2 & 1.9 & 168 \\
Practice composition & 1988 & 220 & 3889 & 762.5 & 168 \\
\% women & & & & & \\
\% elderly & 52.1 & 42.3 & 67.8 & 3.5 & 168 \\
\% 0 4 year & 5.2 & 0.7 & 17.0 & 2.9 & 168 \\
\% public insured & 6.8 & 2.7 & 19.0 & 2.6 & 168 \\
\% unemployed & 60.8 & 31.3 & 83.6 & 10.1 & 168 \\
\% foreign nationality & 4.9 & 1.1 & 17.1 & 2.4 & 168 \\
\% low educated & 2.2 & 0.9 & 12.9 & 2.3 & 168 \\
\hline
\end{tabular}

Due to the stratified character of the sample these descriptive statistics can not be seen as true estimates of population parameters. A weighing procedure has been designed to compute true estimates, but for the purpose of this study, the analysis of relations between list size and practice composition and indicators of workload, this is not necessary.

'Number of contacts during 3 months divided by personal list size.

${ }^{3}$ Only hours in which practice activities were reported, were included.

Only office contacts were included. 
Table 2. Intercorrelations between the indicators of workload

\begin{tabular}{|c|c|c|c|c|c|c|c|}
\hline & $\begin{array}{l}\text { Total } \\
\text { contact } \\
\text { rate }\end{array}$ & $\begin{array}{l}\text { Office } \\
\text { contact } \\
\text { rate }\end{array}$ & $\begin{array}{l}\text { Home } \\
\text { visit } \\
\text { rate }\end{array}$ & $\begin{array}{c}\text { Patient } \\
\text { initiated } \\
\text { contact rate }\end{array}$ & $\begin{array}{c}\text { Total } \\
\text { hours } \\
\text { worked }\end{array}$ & $\begin{array}{l}\text { Hours in } \\
\text { patient } \\
\text { care }\end{array}$ & $\begin{array}{l}\text { Hours } \\
\text { in other } \\
\text { activities }\end{array}$ \\
\hline $\begin{array}{l}\text { Office contact rate } \\
\text { Home visit rate } \\
\text { Patient initiated contact rate } \\
\text { Total hours worked } \\
\text { Hours in direct patient care } \\
\text { Hours in other activities } \\
\text { Average length of } \\
\text { office consultations }\end{array}$ & $\begin{array}{l}0.42 * \\
0.40 * * \\
0.32 * * \\
-0.03 \\
-0.07 \\
0.05 \\
-0.08\end{array}$ & $\begin{array}{c}0.01 \\
0.83^{* *} \\
-0.15^{*} \\
-0.17^{\star} \\
0.00 \\
0.06\end{array}$ & $\begin{array}{c}0.13 \\
0.19^{*} \\
0.25^{*} \\
-0.04 \\
-0.14^{*}\end{array}$ & $\begin{array}{r}-0.10 \\
-0.08 \\
-0.05 \\
0.01\end{array}$ & $\begin{array}{l}0.74^{* *} \\
0.52^{\circ *} \\
0.10\end{array}$ & $\begin{array}{r}-0.20^{*} \\
0.01\end{array}$ & 0.12 \\
\hline
\end{tabular}

When the rate of all contacts in a practice (including contacts handled by practice secretaries) is considered, there is no significant relation with list size. However, in the case of the office contact rates (handled by GPs themselves) a negative relation with list size is found. GPs with larger practices have a lower rate of contacts initiated by patients.

Figure 2 shows that GPs with a larger personal list size work more hours per week. Larger lists coincide with more hours spent in direct patient care. On the other hand, time spent in other activities has no relation with list size.

List size is negatively related to the length of office consultations (see Fig. 3). However, GPs with very large lists (with more than 3000 patients) spent more time on each patient than GPs with 2250-3000 patients.

\subsection{The influence of list size and practice composition}

To determine the relative influence of list size and the characteristics of the practice population on indicators of GP's workload, two-step regression analyses were carried out. In the first step list size is the only independent variable. In the second step list size and characteristics of practice composition (see Section 3) are included. The coefficient of determination $\left(R^{2}\right)$ of these two equations will be compared and the difference will be tested. The contact rates are considered in Table 3.

Personal list size turns out to be a bad predictor of the contact rates of GPs. The first equation explains little or no variance. The inclusion of aspects of practice composition significantly improves the co- efficients of determination. However, the coefficients of most of the equations are still low. Only in the case of home visits about one third of the variance is explained by 'demand-related' determinants of workload. The standardized regression coefficients in the second equation indicate the variables with the strongest contribution. GPs in urban areas have a lower contact rate during three months: even when we control for differences in practice composition and list size. This might be an effect of easier access to alternative sources of health care in urban areas. The age composition of the practice population is an important determinant of contact rates. GPs who have a higher percentage of children under 5 years of age on their list record a higher rate of contacts, especially of office contacts. Home visit rates on the other hand are higher in practices with a larger percentage of elderly. The extra workload in this respect is at least partly compensated by a negative relation of the percentage elderly with the office contact rate. Other factors with significant contributions are the practice composition by gender (in the case of the office contact rate) and education (total contact rate).

In Table 4 a comparable analysis is presented for the number of hours worked. List size explains one fourth of the variation in the number of hours worked per week. Although the inclusion of aspects of practice composition improves the explained variance, the difference between a regression equation consisting of list size and an equation in which practice composition is added is not significant. This means that list size is the most important factor in determining hours worked per week. Time spent in

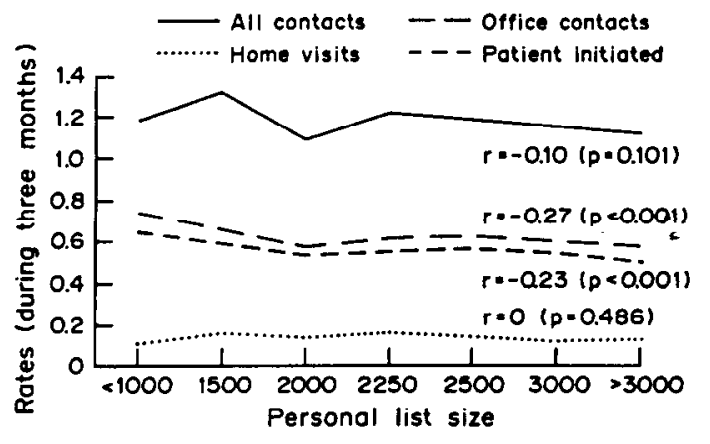

Fig. 1. Contact rates.

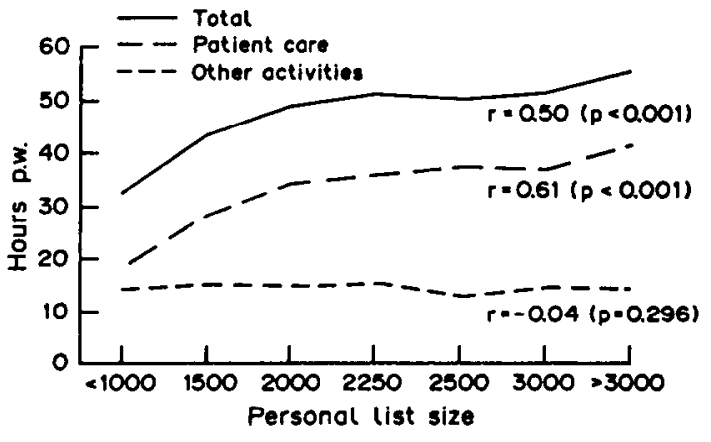

Fig. 2. Hours worked in practice. 


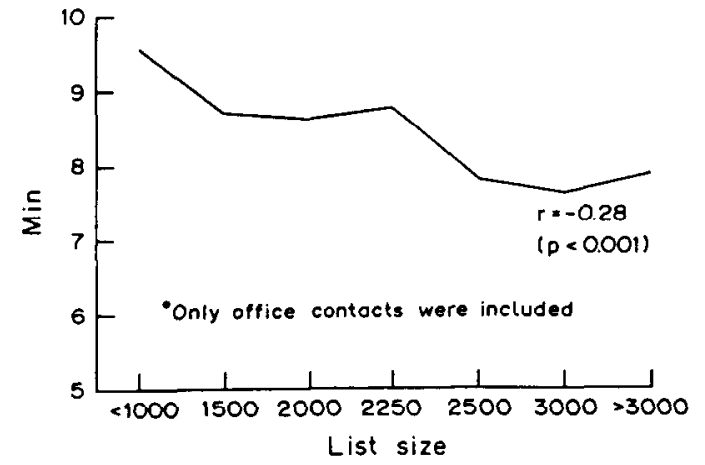

Fig. 3. Average length of consultations.

direct patient care is significantly better predicted when aspects of practice composition are included in the regression equation. The same can be said about the time spent in other activities, like practice administration, post-graduate education and so on. However, the low coefficient of determination in the second equation indicates that factors situated on the 'demand side' have only a very small influence on the hours spent in these activities.

Almost half of the variance in time spent in direct patient care is explained by all 'demand-related' variables. The standardized regression coefficients in the second equation show that list size is still the most important factor when time spent in patient care is concerned. Furthermore, a higher percentage of elderly in the practice population coincides with a larger number of hours spent in direct patient care. This might be a result of GPs visiting elderly people more often at home.

The influence of 'demand-related' variables on the amount of time spent in other activities is rather low: the percentage of elderly and of publicly insured patients are the only two with a significant negative relation. In the case of the elderly this might be

Table 3. Results of two regression equations on contact rates: standardized regression coefficients (beta's) and explained variance

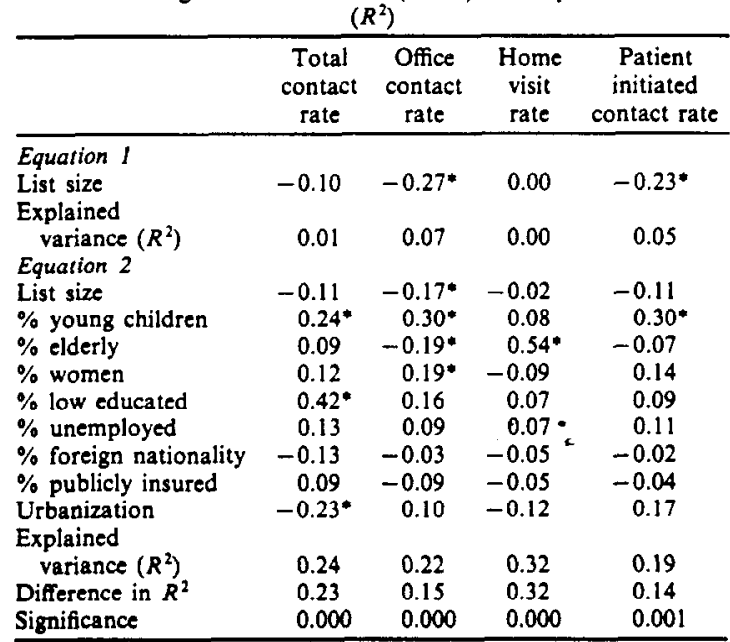

$P<0.05$.
Table 4. Results of two regression equations on hours worked: standardized regression coefficients (beta's) and explained variance $\left(R^{2}\right)$

\begin{tabular}{lccc}
\hline & $\begin{array}{c}\text { Total hours } \\
\text { worked } \\
\text { p.w. }\end{array}$ & $\begin{array}{c}\text { Hours } \\
\text { spent in } \\
\text { patient care }\end{array}$ & $\begin{array}{c}\text { Hours spent } \\
\text { in other } \\
\text { activities }\end{array}$ \\
\hline $\begin{array}{l}\text { Equation } l \\
\text { List size }\end{array}$ & $0.50^{*}$ & $0.61^{*}$ & -0.04 \\
$\begin{array}{l}\text { Explained } \\
\text { variance }\left(R^{2}\right)\end{array}$ & 0.25 & 0.37 & 0.00 \\
$\begin{array}{l}\text { Equation 2 } \\
\text { List size }\end{array}$ & $0.55^{*}$ & $0.64^{*}$ & -0.00 \\
\% young children & 0.02 & 0.05 & -0.03 \\
\% elderly & 0.08 & $0.35^{*}$ & $-0.33^{*}$ \\
\% women & -0.02 & -0.04 & 0.02 \\
\% low educated & 0.02 & -0.14 & 0.21 \\
\% unemployed & 0.11 & -0.02 & 0.17 \\
\% foreign nationality & -0.01 & 0.05 & -0.08 \\
\% publicly insured & -0.21 & 0.06 & $-0.39^{*}$ \\
Urbanization & 0.05 & 0.15 & -0.12 \\
Explained & & & \\
$\quad$ variance $\left(R^{2}\right)$ & 0.30 & 0.48 & 0.12 \\
Difference in $R^{2}$ & 0.05 & 0.11 & 0.12 \\
Significance & 0.260 & 0.000 & 0.019 \\
\hline \% & & &
\end{tabular}

$P<0.05$

caused by GPs needing to spend more time in patient care and a negative relation between time in patient care and in other activities. The influence of the percentage publicly insured patients might be explained by the fact that less administrative procedures have to be carried out for publicly insured patients. Privately insured patients e.g. have to be billed for every consultation.

In Table 5 the results of the two regression analyses on the average length of office consultations are shown.

Only $8 \%$ of the variation in the average length of office consultations is determined by list size. When the aspects of the practice composition are taken into account the explained variance increases signifcantly. GPs with larger lists have on the average shorter consultations than GPs with smaller lists. A larger percentage of unemployed people on a GP's list is associated with longer office consultations. The percentage of publicly insured patients is nega-

Table 5. Results of two regression equations on average length of office consultations: standardized regression coefficients (beta) and explained variance

\begin{tabular}{lc}
\multicolumn{2}{c}{$\begin{array}{c}\text { regression coefficients (beta) and explained variance } \\
\left(R^{2}\right)\end{array}$} \\
\hline & $\begin{array}{c}\text { Average length of } \\
\text { office consultations }\end{array}$ \\
\hline Equation $I$ & $-0.28^{*}$ \\
List size & 0.08 \\
Explained variance $\left(R^{2}\right)$ & \\
Equation 2 & $-0.16^{*}$ \\
List size & 0.11 \\
$\%$ young children & 0.06 \\
$\%$ elderly & 0.07 \\
$\%$ women & -0.09 \\
$\%$ low educated & $0.30^{*}$ \\
$\%$ unemployed & -0.01 \\
$\%$ foreign nationality & $-0.24^{*}$ \\
$\%$ publicly insured & -0.03 \\
Urbanization & 0.18 \\
Explained variance $\left(R^{2}\right)$ & 0.10 \\
Difference in $R^{2}$ & 0.013 \\
Significance & \\
\hline
\end{tabular}


tively related to the average length of office consultations.

In these regression analyses only independent effects of list size and indicators of practice composition on aspects of workload are described. However, it is conceivable that there are also interaction effects between list size and indicators of practice composition, in the sense that e.g. the percentage of elderly on the GP's list has a different effect on workload in larger practices compared to smaller ones. Interaction effects have been explored by reanalyzing the data separately for GPs with personal list sizes below 2000 patients and above 2000 patients. As far as contact rates are concerned, total contact rate is lower for smaller practices in urbanized areas. In the case of larger practices urbanization has no influence on total contact rates. The office contact rate for larger practices is not affected by practice composition, but it is for smaller practices. No interaction effects have been detected for the other contact rates.

In the group of GPs with smaller practices practice composition has no influence on total hours worked per week and hours spent in patient care. For these smaller practices the number of hours spent in nonpatient-related activities is not related to list size nor to practice composition. However, in larger practices each of the indicators of the number of hours worked by a GP is affected by practice composition.

With regard to the average length of office consultations no interaction effects have been found.

\section{DISCUSSION}

A basic assumption underlying undifferentiated capitation payment of GPs is that list size is the main determinant of their workload. In this article we have tested this assumption by comparing the influence of list size and characteristics of the composition of the GPs' lists on different indicators of workload.

Calnan and Butler [5] tried to assess the degree that the workload of GPs is demand led. They found that list size was particularly important in explaining variations in the number of hours spent in surgery consultation and surgery consultation rates. The research presented here corroborates their findings. List size turned out to have the strongest influence on the number of hours spent in patient care and amongst the contact rates list size has a significant (and negative) relation with the office contact rate. Calnan and Butler also report only a weak association of list size and consultation length as measured by the booking intervals. They conclude that list size is an insensitive measure of patient demand in the sense that it does not take into account the prevalence or severity of illness in the practice population. In our analysis we went one step further by including indicators of the practice composition. Although these are not direct measures of the prevalence and severity of disease in the practice population, they are indirect measures because they have been chosen to represent groups of the population that make higher demands on GPs' services.

Our analysis shows that list size is the main determinant of the total number of hours worked by GPs. The relation is stronger if we only look at the hours in patient-related activities. Composition of the practice also has a significant influence on these indicators of workload. Time spent in non-patient-related activities is only influenced by some aspects of the practice composition. Approximately half of the variation in hours in direct patient care is explained by 'demand-related' characteristics of the practice. Only $10 \%$ of the variance in the non-patient-related activities is explained.

In contrast to what is found in the (mainly British) literature, we only find a negative relation between list size and office contact rate, but not for the total contact rate and home visit rate. These rates are more influenced by characteristics of the practice composition, but the explained variance is still low. When we look at the total contact rate, which also includes contacts that have been handled by the practice secretary (such as repeat prescriptions), it seems that larger list size in the Netherlands does not affect the accessibility of the practice. However, the office contact rate with the GP is negatively related to list size (but not very strongly), suggesting that delegation of work towards the practice secretary is a coping strategy for the higher demands of a larger list size in the Netherlands.

Except for the home visit rate, the total hours worked and particularly for the hours spent in direct patient care, demand-related variables are not important determinants of workload as judged from the coefficients of determination in the regression analyses. It may be assumed that the GP's own decisions on how to allocate his time and the organization of the practice (including delegation towards practice secretaries) are of more importance.

Flat capitation rates reflect the GP's involvement in direct patient care relatively well; differentiation of capitation fees according to practice composition improves that situation and also better reflects the activities of GPs in different kind of contacts, particularly for home visits.

However, when one also values non-patientrelated activities, not only administrative in kind, but also related to post-graduate education and peer review and cooperation within the primary health care team, a system like the pre-1990 contract in the U.K. with a fixed allowance, apart from capitation would do more justice to the GP's workload.

\section{REFERENCES}

1. Ball J. G. Workload in general practice. Br. Med. J. 1, 868-870, 1978. 
2. Fleming D. M. The case for differential capitation fees based on age in British general practice. Br. Med. J. 297, 966-968, 1988.

3. Wal G. van der. Voor een differentiering binnen het abonnementshonorarium. Huisarts Wetenschap 27, suppl., 68-71, 1984.

4. Groenewegen P. P. and Hutten J. B. F. Workload and job satisfaction among general practitioners: a review of the literature. Soc. Sci. Med. 32, 1111-1119, 1991.

5. Calnan $M$. and Butler $J$. R. The economy of time in general practice: an assessment of the influence of list size. Soc. Sci. Med. 26, 435-44I, 1988.

6. Dam F. van, Pool J. and Hingstman L. Figures from the Information System on Professionals in Dutch Primary Health Care for 1988. NIVEL, Utrecht, 1989.

7. Flierman H. A. and Groenewegen P. P. Het Deense voorbeeld: een gemengd systeem van honorering per verrichting en abonnement. Huisarts Wetenschap 32, 212-218, 1989.

8. Knight $R$. The importance of list size and consultation length as factors in general practice. $J$. $R$. Coll. gen. Pract. 37, 19-22, 1987.

9. Wilkin D., Hodgkin P. and Metcalfe D. Factors affecting workload: is received wisdom true? In The Medical Annual, 1986. The Yearbook of General Practice (Edited by Pereira Gray D. J.). Wright, Bristol, 1986.

10. Armstrong D. and Griffin G. A. Patterns of work in general practice in the Bromley Health District, $J$. $R$. Coll. gen. Pract. 37, 264-266, 1987.

11. Fleming D. M. Consultation length (letter to the editor). J. R. Coll. gen. Pract. 37, 179, 1987.

12. Zee J. van der. De Vraag Naar Diensten van de Huisarts. Utrecht, NHI, 1982.

13. Marsh G. N. and McNay R. A. Factors affecting workload in general practice-II. Br.- Med. J. 4, 319-321, 1974.
14. Yuen P. and Balarajan R. Unemployment and patterns of consultations. Br. Med. J. 298, 1212-1214, 1989.

15. Vliet R. C. J. A. van and van de Ven W. P. M. M. Consumptieverschillen tussen ziekenfonds- en particulier verzekerden nader onderzocht. Gezondheid $\mathrm{Sa}$ menleving 7, 81-94, 1986.

16. Mootz M. The need for health care utilization and its relation to insurance coverage for medical expenses. Gezondheid Samenleving 6, 232-237, 1985.

17. Morrell D. C., Evans M. E., Morris R. W. and Roland $M$. $O$. The 'five minute' consultation: effect of time constraint on clinical content and patient satisfaction. Br. Med. J. 292, 870-873, 1986.

18. Westcott $R$. The length of consultations in general practice. J. R. Coll. gen. Pract. 27, 552-555, 1977.

19. Verhaak P. F. M. Bewerkelijkheid van huisartsconsulten met verschillende klachten of patiënten, uitgedrukt in tijd. Tijdschrift Sociale Gezondheidszorg 64, $558-562,1986$.

20. Joseph A. E. and Phillips D. R. Accessibility and Utilization: Geographical Perspectives on Health Care Delivery. Harper \& Row, New York, 1984.

21. Bensing J. M., Foets M., van der Velden J. and van der Zee J. De nationale studie van ziekten en verrichtingen in de huisartspraktijk, achtergronden en methoden. Huisarts Wetenschap 34, 51-61, 1991.

22. Incidental differences in the number of hours worked due to hours on duty can be reduced by only including hours worked during (more or less arbitrarily defined) office hours (8:00 hr a.m. till 5:00 hr p.m.). However, this does not affect our findings. In another analysis this more restricted definition of hours worked has been used. Compare Calnan M., Groenewegen P. P. and Hutten J. B. F. Professional reimbursement and management of time of general practitioners, an international comparison (submitted). 